\title{
Analisa Pola Peminjaman Buku Perpustakaan Menggunakan Algoritma Apriori
}

\author{
Azwar Anas \\ Program Studi Pendidikan Informatika, STKIP PGRI Sumbar \\ aans07@yahoo.co.id
}

http://dx.doi.org/10.22202/jei.2014.v1i1.1439

\begin{abstract}
ABSTRAK
Data yang dimiliki oleh suatu organisasi merupakan salah satu aset dari organisasi tersebut. Adanya kegiatan operasional sehari-hari akan semakin memperbanyak jumlah data. Jumlah data yang begitu besar justru bisa menjadi masalah bila organisasi tersebut tidak bisa memanfaatkannya. Dalam penelitian ini, peneliti akan menjelaskan algoritma apriori untuk mengelompokkan data peminjaman buku SMPN 24 Padang berdasarkan kecenderungannya yang muncul bersamaan dalam suatu kegiatan kunjungan pustaka. Dalam melakukan proses peminjaman buku, tentu saja data mentah akan diolah dengan membaginya kedalam pecahan-pecahan data yang berbeda. Diantara tabel data peminjaman buku yang diolah adalah tabel peminjaman secara umum, tabel kandidat 2-itemset, tabel kandidat 3-itemset, tabel tabular peminjaman, tabel nilai support, tabel nilai confidence dan mendapatkan pola peminjaman buku. Dengan mendapatkan pengetahuan dari algoritma ini, dapat dijadikan rujukan bagi pihak sekolah dalam pengadaan buku-buku perpustakaan di SMPN 24 Padang.
\end{abstract}

Kata kunci : data mining, algoritma apriori

\section{PENDAHULUAN}

Data yang dimiliki oleh suatu organisasi merupakan salah satu aset dari organisasi tersebut. Adanya kegiatan operasional sehari-hari akan semakin memperbanyak jumlah data. Jumlah data yang begitu besar justru bisa menjadi masalah bila organisasi tersebut tidak bisa memanfaatkannya. Semakin banyak data, akan semakin diperlukan usaha untuk memilah data mana yang bisa diolah menjadi informasi. Jika data dibiarkan saja, maka data tersebut hanya akan menjadi sampah yang tidak berarti bagi organisasi tersebut.

Oleh karena itu, diperlukan sebuah aplikasi yang mampu memilah dan memilih data yang benar sehingga bisa diperoleh informasi yang berguna bagi penggunanya.
Dalam penelitian ini, peneliti akan menjelaskan cara menggunakan aplikasi untuk mengelompokkan data pengunjung perpustakaan SMPN 24 Padang berdasarkan kecenderungannya yang muncul bersamaan dalam suatu kegiatan peminjaman buku pustaka menggunakan algoritma apriori.

Algoritma apriori termasuk jenis aturan asosiasi pada data mining. Selain apriori, yang termasuk dalam golongan ini adalah metode Generalized Rule Induction dan Algoritma Hash Based.

Aturan yang menyatakan asosiasi antara beberapa atribut sering disebut affinity analysis atau market basket analysis.

Penerapan algoritma apriori telah banyak digunakan sebelumnya untuk mendapatkan ifnormasi berharga dari sejumlah frekuensi data. Berikut beberapa 
penerapan algoritma apriori yang telah dilakukan :

a. Prediksi Mata Kuliah Pilihan dengan Aturan Asosiasi (Widodo, 2008)

b. Analisis Market Basket dengan Algoritma Apriori dan FP-Growth (Erwin, 2009).

Tugas dari data mining adalah untuk menghasilkan semua kaidah asosiasi pada suatu tabel transaksional, yang mempunyai nilai support lebih dari minimum support. Kaidah tersebut juga harus mempunyai confidence yang lebih besar dari confidence. Tugas tersebut dapat diselesaikan dengan melakukan 2 tahap penting (Leo Willyanto Santoso, 2003) yaitu :

a. Mencari semua frequent itemset
b. Mencari aturan asosiasi yang
confidence.

\section{LANDASAN TEORI}

\section{Definisi Data Mining}

Menurut Pramudiono (2006), data mining adalah serangkaian proses untuk menggali nilai tambah dari suatu kumpulan data berupa pengetahuan yang selama ini tidak diketauhui secara manual. Menurut Poniah, P (2002), data mining (Penggalian Data) didefinisikan sebagai sebuah proses untuk menemukan hubungan, pola dan trend baru yang bermakna dengan menyaring data yang sangat besar, yang tersimpan dalam penyimpanan, menggunakan teknik pengenalan pola seperti teknik statistic dan matematika. Menurut David Han (2001), data mining atau KDD adalah proses untuk menemukan interesting knowledge dari sejumlah besar data yang disimpan baik di dalam databases, data warehouses atau tempat penyimpanan informasi lainnya. Secara sederhana data mining adalah ekstraksi informasi atau pola yang penting atau menarik dari data yang ada di database yang besar (Gregorius dkk, 2009).

\section{METODOLOGI PENELITIAN}

Dalam melakukan sebuah penelitian, tentu harus berdasarkan metodologi penelitian yang benar sehingga dapat mempermudah jalannya penelitian tersebut. Metodologi penelitian merupakan kerangka kerja dalam melakukan penelitian. Dengan mengikuti kerangka kerja tersebut maka penelitian yang dilakukan akan berjalan dengan sistematis dan memberikan hasil yang baik.

\section{Kerangka Kerja}

Pada bab ini akan diuraikan kerjangka kerja penelitian, kerangka kerja ini merupakan langkah-langkah yang akan dilakukan dalam penyelesaian masalah yang akan dibahas.

Berdasarkan kerangka kerja pada gambar 3.1. maka masing-masing langkahnya dapat diuraikan seperti berikut ini :

a. Mendefinisikan Ruang Lingkup Masalah Ruang lingkup masalah yang akan diteliti harus ditentukan terlebih dahulu, karena tanpa mampu menentukan serta mendefinisikan batasan masalah yang akan diteliti, maka tidak akan pernah didapat suatu solusi yang terbaik dari masalah tersebut. Jadi langkah pertama ini adalah langkah awal yang terpenting dalam penulisan ini.

b. Analisis Masalah

Langkah analisis masalah adalah untuk dapat memahami masalah yang telah ditentukan ruang lingkup atau batasannya. Dengan menganalisa 
masalah yang telah ditentukan tersebut, maka diharapkan masalah dapat dipahami dengan baik.

Pada bab ini digambarkan proses untuk menentukan pola peminjaman buku perpustakaan dengan menggunakan algoritma apriori. Disamping itu juga diuraikan tentang kebutuhan data untuk menganalisa pola peminjaman buku perpustakaan. Dari hasil analisa tersebut, maka algoritma apriori hendaknya mampu menentukan pola peminjaman buku perpustakaan dengan baik.

\section{c. Penentuan Tujuan}

Berdasarkan pemahaman dari masalah, maka ditentukan tujuan yang akan dicapai dari penulisan ini. Pada tujuan ini ditentukan target yang dicapai, terutama yang dapat mengatasi masalah-masalah yang ada.

d. Mempelajari Literatur

Untuk mencapai tujuan, maka dipelajari berbagai literatur yang relevan dengna masalah yang diteliti. Kemudian literatur-literatur yang dipelajari tersebut diseleksi untuk dapat ditentukan literatur-literatur mana yang akan digunakan dalam penelitian.

Literatur diambil dari internet, yang berupa artikel dan jurnal ilmiah tentang data mining, association rule dan algoritma apriori, serta bahan bacaan lain yang mendukung penelitian.

e. Pengumpulan Data dan Informasi

Dalam pengumpulan data dilakukan observasi yaitu pengmatan secara langsung di tempat penelitian sehingga permasalahan yang ada dapat diketahui dengan jelas. Kemudian dilakukan interview yang bertujuan untuk mendapatkan informasi atau data yang dibutuhkan. Selain itu juga dilakukan studi kepustakaan yaitu dengan membaca bukubuku yang menunjang dalam melakukan pengalisaan terhadap data dan informasi yang didapat.

Adapun data-data yang diperlukan dalam penelitian ini adalah :

a. Data pengunjung perpustakaan berdasarkan total jumlah siswa

b. Data pengunjung perpustakaan berdasarkan tingkat kunjungan harian

c. Data pengunjung perpustakaan dari pihak guru dan pegawai

d. Data buku-buku, majalah, jurnal dan artikel koleksi perlustakaan.

\section{e. Analisa Teknik yang digunakan}

Bagian ini bertujuan untuk menganalisis dan memahami teknik yang akan digunakan dalam pengolahan data yang telah diperoleh dari tempat penelitian, terutama pada proses, yang mana teknik yang digunakan untuk pengolahan data dengan algoritma apriori.

\section{f. Implementasi}

Setelah dilakukan analisa teknik yang digunakan, maka dilakukan implementasi terhadap software dalam hal ini adalah software data mining Orange. Tentu saja penerapan analisa pada software tersebut menggunakan algoritma apriori. Jika penerapan sistem sudah berjalan dengan lancar dan akurat, maka sistem dapat 
diimplementasikan sesuai dengan kebutuhan.

\section{g. Pengujian}

Pengujian dilakukan untuk mendapatkan hasil yang sesuai dengan melakukan perbandingan antara perhitungan manual dan komputerisasi, berikut ini langkahlangkah pengujian yang akan dilakukan :

a. Melakukan pengujian algoritma apriori dengan data kepustakaan untuk menentukan pola pengunjung perpustakaan secara manual

b. Setelah dilakukan perhitungan manual, selanjutnya dilakukan perhitungan menggunakan software data mining Orange dengan memasukkan data-data kepustakaan dan diproses menggunakan algoritma apriori.

c. Tahap terakhir adalah melakukan perbandingan antara perhitungan manual dengan komputerisasi, jika hasil yang dicapai sama atau hampir sama, maka data yang diproses dan teknik yang digunakan telah benar.

\section{ANALISA DAN PERANCANGAN SISTEM}

\section{Analisa Asosiasi dengan Algoritma Apriori}

Analisis asosiasi atau association rule mining adalah teknik data mining untuk menentukan aturan asosiatif antara aturan kombinasi item. Contoh dari aturan asosiatif dari analisis peminjaman buku di perpustakaan adalah mengetahui besarnya kemungkinan seorang pengunjung perpustakaan untuk meminjam buku Matematika bersamaan dengan buku IPA. Dengan pengetahuan tersebut, pengelola perpustkaan dapat mengatur penempatan bukunya.

Dalam menentukan pola peminjaman buku, akan digunakan algoritma apriori. Sehingga akan dapat dianalisa dengan mudah pola-pola pengunjung perpustakaan di SMPN 24 Padang. Data-data pengunjung yang telah dikumpulkan akan diolah dan diproses menggunakan prinsip kerja algoritma apriori yang mampu memecahkan data bersifat frequent itemset atau mencari pola.

Aturan asosiasi biasanya dinyatakan dalam bentuk :

$\{\mathrm{TIK}, \mathrm{MTK}\} \rightarrow\{$ IPA $\}$ support $=$ $40 \%$, confidence $=50 \%\}$

Artinya $50 \%$ dari transaksi peminjaman buku yang memuat buku TIK dan MTK juga memuat buku IPA. Sementara $40 \%$ dari seluruh transaksi peminjaman yang ada memuat ketiga item tersebut.

\section{Menentukan Variabel}

Data yang akan diolah dalam menentukan pola peminjaman buku ini adalah data pengunjung. Adapun variabelvariabel data pengunjung perpustakaan SMPN 24 Padang adalah :
a. Nama
b. Hari/ tanggal
c. Jenis kelamin
d. Kelas
e. Judul buku 1
f. Judul buku 2
g. Judul buku 3

Dari variabel-variabel di atas, setiap pengunjung akan dibagi kedalam kelompok dengan judul buku yang dipinjam sama, hal ini dilakukan agar proses analisa data dapat dilakukan dengan mudah menggunakan algoritma apriori. 


\section{Analisis Frekuensi Tinggi}

Tahapan ini mencari kombinasi item yang memenuhi syarat minimum dari nilai support dalam database. Nilai support sebuah item diperoleh dengan rumus berikut :

Support $(A)=\frac{\text { JumlahtransaksimengandungA }}{\text { Jumlahtransaksi }}$

Sedangkan nilai support dari 2 item diperoleh dari rumus berikut : Support $(A, B)=P(A \cap B)$

Support $(A, B)=$ ¿JumlahtransaksimengandungAdanB EJumlahtransaksi

\section{Melakukan Proses}

Berdasarkan variabel-variabel data pengunjung di atas, maka format data dapat dilihat pada tabel 4.2. berikut ini :

Setelah data pengunjung diperoleh, selanjutnya adalah mengelompokkan pengunjung berdasarkan judul buku yang dipinjam. Namun sebelum hal ini dilakukan, agar mempermudah dalam analisa, maka dibuatlah tabel petunjuk buku berdasarkan mata pelajaran masingmasingnya.

\section{Tabel 4.2. Transaksi Peminjaman Buku}

Puku yang
dipinjam

1 TIK, PKn, Penjaskes

2 PKn, MTK

3 IPA, Penjaskes

$4 \quad$ Agama, PKn, TIK

5 IPA, TIK, Agama

6 TIK

7 IPA, MTK, TIK

8 TIK, Agama,
Penjaskes

9 IPA, TIK, Agama

10 TIK, Agama

$11 \quad$ Penjaskes

12 B. Inggris, MTK, IPA

13 Penjaskes

14 MTK, B. Indonesia

15 IPS

16 MTK, B. Inggris, B. Indonesia

Data transaksional di atas biasanya direpresentasikan dalam bentuk seperti terlihat pada tabel 4.3. berikut ini :

Tabel 4.3. Representasi Data Peminjaman Buku

\section{Pengunjung Buku yang dipinjam}

$\begin{array}{ll}1 & \text { TIK } \\ 1 & \text { PKn } \\ 1 & \text { Penjaskes } \\ 2 & \text { PKn } \\ 2 & \text { MTK } \\ 3 & \text { IPA } \\ 3 & \text { Penjaskes } \\ 4 & \text { Agama }\end{array}$




$\begin{array}{llll}4 & \text { PKn } & 15 & \text { IPS } \\ 4 & \text { TIK } & 16 & \text { MTK } \\ 5 & \text { IPA } & 16 & \text { B. Inggris } \\ 5 & \text { TIK } & 16 & \text { B. Indonesia }\end{array}$

$5 \quad$ Agama

6 TIK

$7 \quad$ IPA

$7 \quad$ MTK

$7 \quad$ TIK

$8 \quad$ TIK

$8 \quad$ Agama

$8 \quad$ Penjaskes

$9 \quad$ IPA

9 TIK

$9 \quad$ Agama

10 TIK

10 Agama

11 Penjaskes

12 B. Inggris

12 MTK

12 IPA

13 Penjaskes

14 MTK

14 B. Indonesia
Jika dibuat dalam bentuk tabular, data transaksi peminjaman buku akan terlihat seperti pada tabel 4.4. berikut.

\section{Tabel 4.4. Tabular Peminjaman Buku}

Misalnya D adalah himpunan transaksi yang direpresentasikan dalam tabel 4.2., di mana masing-masing transaksi $\mathrm{T}$ dalam $\mathrm{D}$ merepresentasikan himpunan item yang berada dalam I. Misalnya, kita memiliki himpunan item A (misalnya MTK dan IPA) dan himpunan item lain B (mislanya Agama). Kemudian, aturan asosiasi akan berbentuk Jika $A$, maka $B\{A \rightarrow B\}$

Di mana antecedent $\mathrm{A}$ dan consequent $\mathrm{B}$ merupakan subset dari I, sedangkan A dan B merupakan mutually exclusive. Definisi tersebut tidak berlaku untuk aturan trivial seperti :

\section{Jika TIK dan IPA maka TIK}

Jika itemset adalah himpunan item yang ada dalam I, dan k-itemset adalah itemset yang berisi $k$ item. Misalnya (IPA, TIK) adalah sebuah 2-itemset dan (Penjaskes, Agama, IPS) merupakan 3itemset. Frequent itemset menunjukkan itemset yang memiliki frekuensi kemunculan lebih dari nilai minimum yang telah ditentukan $(\Phi)$. Misalnya $\Phi=2$, maka semua itemset yang frekuensi kemnculannya lebih dari satu atau sama dengan 2 kali disebut frequent. Himpunan dari frequent k-itemset dilambangkan dengan $F_{k}$. 
Pada pengujian ini, penulis menetapkan nilai minimum support sebesar $5 \%$ dan minimum confidence sebesar $10 \%$. Sehingga data yang akan diproses oleh software Orange hanyalah rule-rule yang memenuhi kriteria di atas. Tabel 4.5. berikut ini menunjukkan calon 2-itemset dari data peminjaman yang memenuhi ketentuan minimum support dan minimum confidence berdasarkan pada tabel 4.2.

\section{Tabel 4.5. Calon 2-itemset}

\section{Kombinasi}

MTK, IPA

Agama, Penjaskes

4

TIK, Agama

9

TIK, IPA

10

TIK, Penjaskes

8

Penjaskes, IPS

IPA, Agama

IPA, TIK

B. Inggris, TIK
Dari tabel 4.5. dapat disimpulkan jika ditetapkan nilai dari threshold di mana $\Phi=$ 2, maka :

$\mathrm{F}_{2}=\{(\mathrm{MTK}, \mathrm{IPA}),($ Agama, Penjaskes $)$, (TIK, Agama), (TIK, IPA), (TIK, Penjaskes), (Penjaskes, IPS), (IPA, Agama), (IPA, TIK), (B. Inggris, TIK)\}.

Tabel 4.6. Calon 3-itemset

\section{Kombinasi Jumlah}

Agama, TIK, Penjaskes

\author{
TIK, IPA, Agama 3 \\ TIK, Agama, Penjaskes 3 \\ IPA, TIK, Agama 3
}

Kombinasi dari itemset dalam $\mathrm{F}_{2}$ dapat kita gabungkan menjadi calon 3-itemset. Itemset-itemset dari $\mathrm{F}_{2}$ yang dapat digabungkan adalah itemset-itemset yang memiliki kesamaan dalam $k-1$ item pertama. Calon 3-itemset yang dapat dibentuk dari $F_{2}$ tampak pada tabel 4.6. Dengan demikian $\mathrm{F}_{3}=$ \{(Agama, TIK, Penjaskes), (TIK, IPA, Agama), (TIK, IPA, Penjaskes), (IPA, TIK, Agama)\}.

\section{Pembentukan Aturan Asosiasi}

Setelah semua pola frekuensi tinggi ditemukan, barulah dicari aturan asosiasi yang memenuhi syarat minimum untuk confidence dengan menghitung confidence aturan asosiasi $\mathrm{A} \rightarrow \mathrm{B}$. Nilai confidence dari aturan $\mathrm{A} \rightarrow \mathrm{B}$ diperoleh dari rumus berikut.

$$
\text { Confidence }=P(\mathrm{~B} \mid \mathrm{A})=
$$

Jika meminjam buku Agama dan TIK, maka akan meminjam buku Penjaskes. Untuk mendapatkan nilai confidence dari aturan ini maka masukkan nilai total transaksi peminjaman yang mengandung buku Agama dan TIK lalu dibagi dengan total transaksi peminjaman yang mengandung buku Agama dan TIK. Rujukan dari rumus ini adalah pada tabel 4.6. dengan 3-itemset dan tabel 4.5. dengan 2-itemset.

Sementara untuk mendapatkan nilai support dari jika meminjam buku MTK, maka akan meminjam buku IPA merupakan hasil dari perhitungan total transaksi mengandung peminjaman buku MTK dan IPA lalu dibagi dengan total transaksi peminjaman. 
Aturan asosiasi yang terbentuk berdasarkan minimum support $5 \%$ dan minimum confidence $10 \%$ dapat dilihat pada tabel 4.7. berikut.

Tabel 4.7. Aturan Asosiasi 2-itemset

\section{Aturan Support Confidence}

$\begin{array}{lll}\text { Jika } & 7 \% & 50 \% \\ \text { meminjam } & & \\ \text { MTK, maka } & & \\ \text { akan } & & \\ \text { meminjam } & & \\ \text { IPA } & & \\ \text { Jika } & & \\ \text { meminjam } & & \\ \text { Agama, maka } & & \\ \text { akan } & & \\ \text { meminjam } & & \\ \text { Penjaskes } & & \\ \text { Jika } & & \\ \text { meminjam } & & \\ \text { TIK, maka } & & \\ \text { akan } \\ \text { meminjam } \\ \text { Agama }\end{array}$

Jika $7 \%$

meminjam

Penjaskes,

maka akan

meminjam IPS

Jika $8 \%$

$50 \%$

meminjam

IPA, maka

akan

meminjam

Agama

Jika

$11 \%$

$55 \%$

meminjam

IPA, maka

akan

meminjam

TIK

Jika

$8 \%$

$50 \%$

meminjam B.

Inggris, maka

akan

meminjam

TIK

Dari tabel 4.7. dapat disimpulkan nilai support dan confidence dengan acuan 2itemset yang memiliki nilai tertinggi adalah kombinasi antara buku Agama dan buku Penjaskes dengan total support $X$ confidence adalah $80 \%$.

Sementara aturan asosiasi dengan 3itemset yang memenuhi kriteria minimum support dan minimum confidence dapat dilihat pada tabel 4.8. berikut.

Tabel 4.8. Aturan Asosiasi 3-itemset Aturan Support Confidence
Jika meminjam
$6 \%$
$100 \%$ 


maka akan
meminjam
Penjaskes
Jika meminjam
TIK dan IPA,
maka akan
meminjam
Agama
Jika meminjam
TIK dan Agama, $6 \%$
maka akan
meminjam
Penjaskes
Jika meminjam
IPA dan TIK,
maka akan
meminjam
Agama

Dari tabel 4.8. diperoleh 4 aturan asosiasi yang memenuhi syarat minimum support dan minimum confidence. Dapat pula disimpulkan bahwa semua kombinasi peminjaman buku Agama, TIK dan Penjaskes di perpustakaan SMPN 24Padang memiliki tingkat kemungkinan peminjaman secara bersamaan sama tinggi.

\section{PENGUJIAN DAN IMPELEMENTASI}

\section{Hasil Pengujian}

Pengujian terhadap hasil analisa, sangat penting dilakukan untuk menentukan dan memastikan apakah hasil analisa tersebut benar atau tidak.

Untuk menguji kebenaran dari hasil pengolahan data yang dikerjakan secara manual pada BAB IV tersebut kita dapat menggunakan salah satu software aplikasi
Orange dengan langkah-langkah sebagai berikut :

a. Seluruh variabel-variabel (terdiri dari atribut buku yang akan dipinjam, dalam hal ini terdapat 9 jenis buku sebagai sampel dan maksimal peminjaman buku dalam 1 transaksi adalah 3) yang digunakan untuk menentukan pola pengunjung perpustakaan disimpan pada Microsoft Excel dengan nama file BUKU.xls (yang berisi kasus atau krtieria dalam menghasilkan rule) seperti terlihat pada gambar 5.1.

Gambar 5.1. merupakan file yang berisi data peminjaman buku dengan tiga variable, dimana B1 berarti peminjaman buku 1, B2 jika meminjam 2 jenis buku dan B3 jika meminjam sampai tiga jenis buku. Gambar 4.5. masih disimpan dalam format excel standar, agar file ini dapat diakses oleh software Orange, maka harus dilakukan perubahan extensi terlebih dahulu. Karena salah satu tipe data yang dikenal Orange adalah CSV (Comma Delimited). Langkah-langkah dalam mengubah format data tersebut dipaparkan dalam langkah kedua berikut.

b. Selanjutnya file tersebut disimpan kembali dengan extensi csv. Lalu, buka file tersebut dari dari notepad, atau editor teks lainnya, lakukan perubahan tanda pemisah data, yaitu dari tanda ";" (titik koma) menjadi tanda "," (koma) dan data sudah berubah dalam format commaseparated seperti gambar 5.2. berikut.

c. Buka software Orange hingga tampil halaman berikut. 
Gambar 5.3. memperlihatkan menu utama yang ada dalam software Orange, diantaranya menu Data, Visualize, Calassify, Regression, Evaluate dan Unsupervised.

d. Untuk membuka file BUKU.csv, klik Data $\rightarrow$ File, klik kanan pilih open dan cari di mana file disimpan.

Gambar 5.4. memperlihatkan proses akses database yang akan diproses melalui software Orange. Dalam hal ini file yang akan diakses adalah file BUKU.csv yang berisi data-data peminjaman buku perpustakaan SMPN 24 Padang.

e. Setelah data berhasil diakses, langkah selanjutnya adalah menghubungkan menu AssociationRules dengan cara mengklik menu Association Rules $\rightarrow$ Association Rules Explorer untuk mendapatkan rule-rule yang mungkin terjadi. Gambar 5.5. memperlihatkan hubungan antara file yang telah diakses dan rule asosiasi yang akan dicari. Data yang telah diakses akan diproses oleh menu Association Rules dan akan ditampilkan melalui menu Association Rules Explorer.

f. Setelah dihubungkan antara file dan rule asosiasi. Lakukan pengaturan nilai minimum support dan minimum confidence dalam penelitian ini penulis menetapkan $5 \%$ untuk minimum support dan $10 \%$ minimum confidence. Gambar 5.6. memperlihatkan halaman pengaturan minimum support dan minimum confidence. Langkah-langkahnya adalah dengan mengklik kanan menu Association Rules $\rightarrow$ Open sehingga tampail sebagaimana gambar 5.6. di atas.

g. Untuk melihat rule-rule yang terbentuk, klik kanan Association Rules Explorer dan pilih Open, maka rule-rule yang memenuhi kriteria minim support dan minimum confidence yang telah ditetapkan akan ditampilkan sebagaimana gambar 5.6. berikut.

Gambar 5.6. memperlihatkan rule-rule asosiasi ang terbentuk setelah software Orange memproses database yang telah diakses. Rule asosiasi yang terbentuk ialah :

a. Jika meminjam buku Agama, maka akan meminjam buku TIK dengan support $5 \%$ dan confidence $50 \%$

b. Jika meminjam buku TIK, maka akan meminjam buku Agama dengan support $5 \%$ dan confidence $40 \%$.

Dari rule di atas, ternyata buku Agama dan TIK menjadi buku yang paling sering dipinjam secara bersamaan oleh pengunjung perpustakaan SMPN 24 Padang.

\section{PENUTUP}

\section{Kesimpulan}

Dari uraian pada bab-bab yang sudah dibahas sebelumnya dapat ditarik kesimpulan :

a. Algoritma Apriori yang diproses dengan software Orange lebih efektif dan fleksibel digunakan untuk menentukan pola pengunjung perpustakaan

b. Pemilihan variabel yang digunakan sangat mempengaruhi rule atau knowledge yang dihasilkan

c. Sistem yang dibangun dapat membantu dalam menentukan pola pengunjung perpustakaan yang umumnya masih dilakukan secar manual

d. Algoritma Apriori dengan rule asosiasinya dapat memberikan informasi efektif untuk 
menggambarkan proses yang terkait dengan pola penungjung perpustakaan

e. Rule-rule yang dihasilkan dapat digunakan sebagai referensi dalam pengadaan buku-buku koleksi di perpustakaan SMPN 24 Padang.

\section{Saran}

Pengembangan sistem ini adalah dari sistem manual atau berdasarkan basis pengetahuan ke sistem komputerisasi yang dibangun yang dibangun atas dasar pertimbangan permasalahan-permasalahan yang timbul dari sistem yang lama. Berikut ini adalah saran yang dapat diperlihatkan untuk masa yang akan datang.

a. Pada penelitian ini, penulis mencoba salah satu teknik yang digunakan dalam menentukan pola pengunjung perpustakaan yaitu Algoritma Apriori. Untuk mendapatkan hasil pola yang baik dapat digunakan beberapa atau penggabungan beberapa teknik prediksi. Oleh sebab itu perlunya dilakukan penelitian lanjut untuk membandingkan hasil pola dan menentukan teori mana yang menghasilkan prediksi yang terbaik.

b. Untuk mendapatkan haisl pola pengunjung yang baik diperlukan sumber data yang lengkap. Oleh sebab itu diharapkan pada proses penyimpanan data kepustakaan sudah dilakukan secara elektronik dengan demikian akan memudahkan dalam pencarian data yang dibutuhkan untuk melakukan proses penemuan knowledge seperti untuk menentukan pola pengunjung perpustakaan.

c. Walaupun aplikasi ini sangat mudah untuk dijalankan, namun perlu diasosiasikan cara-cara pengoperasiannya.

\section{DAFTAR PUSTAKA}

Di Asih I Maruddani1, Diah Safitri2. "Vector Autoregressive (VAR) untuk Peramalan Harga Saham PT Indofood Sukses Makmur Indonesia TBK'. Semarang, (2008).

Erwin. "Analisis Market Basket dengan Algoritma Apriori dan FP-Growth", (2009).

Kusrini dan Luthfi Taufiq Emha., "Algoritma Data Mining". Yogyakarta : Andi, (2009)

Kusrini. "Konsep dan Aplikasi Sistem Pendukung Keputusan". Yogyakarta, (2009).

Luthfi Taufiq Emha. "Penerapan Data Mining Algoritma Asosiasi untuk Meningkatkan Penjualan". Yogyakarata, (2009).

Magdalena Karismariyanti1, Dhinta Daramantoro2, Dana Sulistyo Kusumo3. "Aturan Asosiasi Spasial pada Basis Data Spasial". Bandung, (2007).

Santoso Willyanto Leo.. "Pembuatan Perangkat Lunak Data Mining untuk Penggalian Kaidah Asosiasi menggunakan Metode Apriori", (2003)

Widodo.. "Prediksi Mata Kuliah Pilihan dengan Aturan Asosiasi" Jakarta, (2008) 